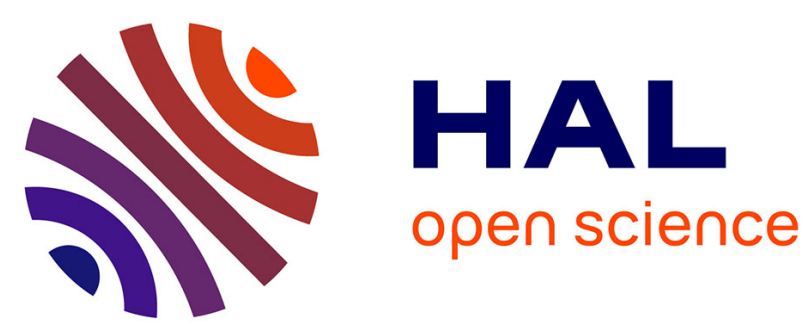

\title{
CHARACTERIZATION OF MULTILAYERS ADHERENCE ON GaAs SUBSTRATE BY INFRARED IMAGING AND CORRELATION TO ASSOCIATED MICROSCOPY STUDIES
}

J. Teillerie, M. Tholomier, J.E Bresse

\section{To cite this version:}

J. Teillerie, M. Tholomier, J.E Bresse. CHARACTERIZATION OF MULTILAYERS ADHERENCE ON GaAs SUBSTRATE BY INFRARED IMAGING AND CORRELATION TO ASSOCIATED MICROSCOPY STUDIES. Journal de Physique IV Proceedings, 1991, 01 (C6), pp.C6-253-C6-257. 10.1051/jp4:1991639 . jpa-00250725

HAL Id: jpa-00250725 https://hal.science/jpa-00250725

Submitted on 1 Jan 1991

HAL is a multi-disciplinary open access archive for the deposit and dissemination of scientific research documents, whether they are published or not. The documents may come from teaching and research institutions in France or abroad, or from public or private research centers.
L'archive ouverte pluridisciplinaire HAL, est destinée au dépôt et à la diffusion de documents scientifiques de niveau recherche, publiés ou non, émanant des établissements d'enseignement et de recherche français ou étrangers, des laboratoires publics ou privés. 


\title{
CHARACTERIZATION OF MULTILAYERS ADHERENCE ON GaAs SUBSTRATE BY INFRARED IMAGING AND CORRELATION TO ASSOCLATED MICROSCOPY STUDIES
}

\author{
J.M. TEILLERIE, M. THOLOMIER and J.F. BRESSE* \\ Laboratoire de Génie Electronique de Marseille (LaGEM), Campus Universitaire de St. \\ Jérôme, Avenue de l'Escadrille Normandie-Niemen, F-13397 Marseille Cedex 13, France \\ *Centre National d'Etudes des Télécommunications, Groupement PMM, Département MPM, \\ 196 avenue Henri Ravera, F-92220 Bagneux, France
}

\begin{abstract}
The adherence of metallic multilayers in III-V compound devices (W-Mo-Ge deposited on $\mathrm{Ga}$ As substrate) has been studied by different characterization techniques : infrared imaging, scanning electron microscopy and localized $X$ ray analysis. The observations realized using infrared emission permit to identify the blistering effect of the deposited layers. The thermal images are in good agreement with topographic images realized by scanning electron microscopy. Moreover the localized $X$ ray analysis of the blisters indicate that the adherence defect concerns the initial Ge/GaAs interface. Infrared emission imaging appears as a non destructive method which may be a useful tool for this kind of problem.
\end{abstract}

\section{Introduction.}

Infrared (IR) technique has proved to be very powerful for material and device analysis. This technique is based upon the detection of IR energy transmitted, reflected or emitted by a target.

Currently the major fields of IR studies are microscopy and thermal imaging. IR microscopy permits to observe samples illuminated by IR light : so it is a useful and nondestructive technique to visualize internal structure (such as decorated dislocations, segregation effect, precipitates,...) in Silicon or GaAs which presents good transparency in the near IR (850 nm - $1250 \mathrm{~nm}) / 1 /, 12 /$.

On the other hand the thermal imaging uses only the IR energy emitted by a sample to build up an image. However a problem in using IR measures to determinate temperature is that the detected signal depends in a critical way of numerous factors like surface sample emissivity and background conditions (parasitic reflexions).

In this paper, we are going to present first results on the application of thermal imaging to the study of adherence problem of metallic layer W/Mo/Ge deposited on GaAs substrate. Local non adherence induces a "blistering" effect which may be visualized using emissivity mapping or thermal image. We show here that the IR signal may be correlated to scanning electron microscopy (SEM) observations and $X$ ray microanalysis. 
The monitoring of the surface temperature may also be realized in using local thermal excitation of the sample by an electron beam.(scanning electron acoustic microscopy : SEAM). Results obtained with IR imaging are in good agreement with SEAM images / $3 /$.

\section{Experimental.}

IR Physics and associated thermal measurement methods have been developped these last few years $/ 4 I, 15 /, 16 /$.

The IR measures were performed using a thermal microimager (COMPUTHERM II) supplied by EDO Corporation (Barnes Engineering Div.). This apparatus the specific features described hereafter.

The system is divided in two coincident optical systems : visual and infrared. Only one lens is used to focus the IR energy on the detector. The IR lens is pierced by a small central hole in which is mounted a glass lens and a $45^{\circ}$ mirror which directs the visible scene to the eye piece. When the IR scanning system is focused on the sample, the conjugate image of the detector focused on the target defines the spot. This spot is scanned over the target in two directions by galvanometer driven $X$ and $Y$ mirrors.

The radiated energy is detected by a inSb photovoltaîc detector cooled at $-195^{\circ} \mathrm{C}$ by liquid nitrogen. The detection spectral domain goes from $1.5 \mu \mathrm{m}$ to $5.5 \mu \mathrm{m}$ with a response nearly flat. The lateral spatial resolution of the images (radiance, emissivity, temperature) is limited by the geometrical dimensions of the spot size. (Typical : $75 \mu \mathrm{m}$ for $\times 5$ objective lens). The physical limitation of spot size is due to the diffraction aberration and consequently to the wavelength of the radiation detected. The thermal resolution is $0,1^{\circ} \mathrm{C}$ for a sample for an average temperature of $75^{\circ} \mathrm{C}$.

The thermal images furnished by the COMPUTHERM II are "true" thermal images. Theses images (128 pixel $\times 128$ pixel) are calculated using the following specific method. Assuming the sample is opaque and the substrate is at the same temperature that the sample, the radiance $N_{M}$ measured at each pixel is given by:

$$
N_{M}=\varepsilon N_{T}+(1+\varepsilon) N_{A}
$$

$\varepsilon:$ emissivity of the target,

$N_{T}$ : blackbody radiance corresponding to the unknown surface temperature,

$\mathrm{N}_{\mathrm{A}}$ : ambient radiance (reflection of radiations surrounding the target).

Assuming stable room temperature and all external conditions, the emissivity of each pixel of the sample may be calculated with two measurements $N_{M 1}, N_{M 2}$ of radiance at two known different temperatures, $T_{1}, T_{2}$, i.e :

$$
\varepsilon=\frac{N M 1-N M 2}{N_{T 1}-N_{T 2}}
$$


The radiances $N_{T 1,2}$ are determined from the temperatures $T_{1,2}$ using tables stored in the system. (The PLANCK low is approximated by a serie expansion).

Once the emissivity image is found, another scan at a fixed temperature serves to determine $N_{A}$ for each point.

At last, the temperature of each point can be calculated from $N_{T}$ (using the values determined for e and $N_{A}$ ) by :

$$
N_{T}=\frac{N_{M}-(1-\varepsilon) N_{A}}{\varepsilon}
$$

and look-up tables of temperatures equivalent black-body radiances.

The emissivity and temperature images calculated from IR measurements have been correlated with scanning electron microscopy (SEM) observations. These observations have been realized with a SEM 515 Philips. This instrument uses a high brightness source (La $B_{6}$ gun) and has got a $8 \mathrm{~nm}$ lateral spatial resolution in secondary electrons imaging. It is fitted with a multifunction detector system (using four THORNLEY-EVERHART type detectors) which allows secondary electrons (topographic contrast) and backscattered electrons (chemical contrast) detection modes. The SEM is fitted also with a EDAX 9900 system which permits $X$ ray microanalysis ( $\mathrm{Si}(\mathrm{Li})$ detection unit).

All theses techniques have been applied to the characterization of adherence problems of metallic layers W $(300 \mathrm{~nm}) / \mathrm{Mo}(100 \mathrm{~nm}) / \mathrm{Ge}(100 \mathrm{~nm})$ deposited on GaAs by electron beam evaporation. The adhesion of the layers critically depends of the substrate preparation (cleaning process) and the deposition conditions (technique, vacuum, ...). Experiment shows that strong adherence problems are found for W/Mo/Ge/Ge/GaAs. (air bubbles between metallic layers and substrate, blistering effect,...).

\section{Results and discussion.}

The samples (W(300 nm)/Mo $(100 \mathrm{~nm}) / \mathrm{Ge}(100 \mathrm{~nm})$ GaAs substrate) were sticked with a thermal bond on a small piece of brass (naturally oxidized) and put onto a heating cooling specimen holder using Peltier effect. Thanks to the procedure described in par.ll, two types of IR observations have been done : emissivity and temperature imaging. In fig. 1a, one may observe a large zone exhibiting an emissivity $\varepsilon$ near 0,2 and small areas characterized by higher emissivity. The temperature image (fig. 1b) presents similar characteristics. 

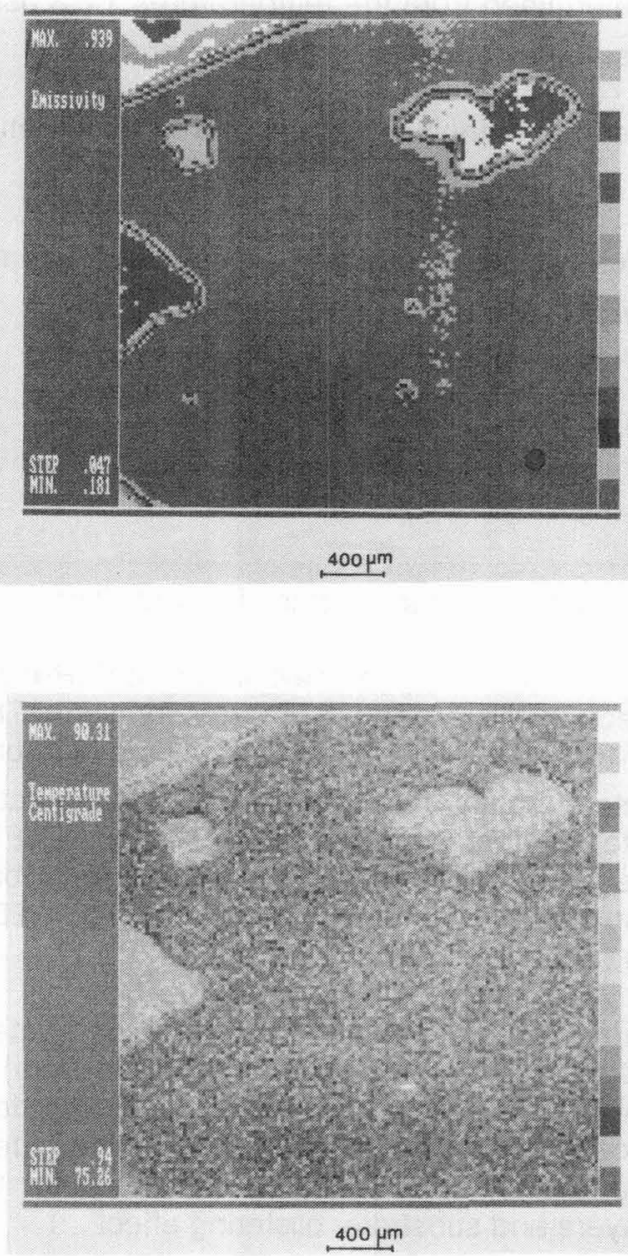

Fig.1. : W $(300 \mathrm{~nm}) / \mathrm{Mo}(100 \mathrm{~nm}) / \mathrm{Ge}(100 \mathrm{~nm})$ deposited on GaAs by electron beam evaporation observed by IR imaging. (a) Emissivity image - (b) Thermal image.

All results presented here are qualitative and need to be interpreted with many carefulness. Indeed in this wavelength range, the $400 \mu \mathrm{m}$ GaAs substrate may be considered as semi-transparent for IR radiation. Elsewhere, tungsten, molybdenum and germanium cannot be considered as bulk material. Therefore the energetic assessment is difficult to realize. For the emissivity image, the 0,2 value determinated for large zone is obviously correlated to the presence of metallic multilayers and particularly to $W$ presence. But we cannot conclude on the emissivity value of the $300 \mathrm{~nm} W$ layer. The high emissivity observed on blister seems rather surprising because the spectral emissivity of GaAs is nearly zero in the 1.8-5.5 $\mu \mathrm{m}$ wavelength range whatever the temperature is. Actually, due the semitransparency of AsGa, it is rather probable that we "see" the brass stand. The temperature image exhibits large temperature differences $\left(1^{\circ} \mathrm{C}\right.$ to $\left.2^{\circ} \mathrm{C}\right)$ which seems too much important to be significant. As explained previously, the characteristics $(\varepsilon, T)$ of blisters correspond roughly to the "background conditions" determinated by brass stand and specimen holder : 
this explains the higher average temperature. The higher temperatures observed at some boundary of the blisters might due to geometrical effects (as the emissivity follows LAMBERT's law) or spurious reflections.

The samples were also observed by SEM. Topographic contrast is obvious by secondary electrons imaging. Thanks to a large atomic number difference, the chemical contrast is high.

The blisters observed with SEM or with IR imaging are well identifiable in the resolution limit of the IR apparatus. Localized $X$ ray microanalysis have been made on blisters, deposit and GaAs substrate. The recorded spectra indicate that all deposited layers (W, Mo, Ge) were unsticked. Considering the layers fragility it would be very interesting to be able to make characterization (SEM, IR, ...) to the different steps of the process in order to get a better understanding of the adherence mechanisms.

\section{Conclusion.}

Different non destructive characterization have been used to make the adherence problem of multilayers deposited on GaAs substrate appear. Blistering effect may be observed using IR radiation emitted by the sample. Interpretation of $I R$ informations needs many care as experimental artefacts are always possible. The modelization of the thermal effect is difficult (lack of informations on IR characteristics, on their variation with surface condition,...). Nevertheless IR imaging appears in this case as a good qualitative investigation method providing results well correlated to other techniques.

\section{References.}

11/ COHEN B.G., Infrared microscopy for evaluation of silicon devices and die attach bonds, Proceedings of the Society of Photo-optical Instrumentation Engineers, vol.104, 125-131 (1977).

12/ KHURANA N., Pulsed infra-red microscopy for debugging latch up on C.MOS products. Proceedings of the International reliability Physics Symposium (April 3-5, 1984).

13/ BRESSE J.F., Use of the scanning electron acoustic microscopy (SEAM) for the study of III.V Compound Semi-conductors. Scanning, vol.2, 308-314 (1990).

14/ TOULOUKIAND E., DEWITT S., PlenumThermophysical Properties of Matter, volumes 7,8,9, Plenum Press (1970).

15/ SIEGEL R., HOWELL J.R., Thermal radiation heat transfer, Mac Graw-Hill Book Company (1972).

16/ GAUSSORGUES G., La Thermographie Infra-Rouge, Technique et Documentation, Lavoisier (1984). 